\title{
Synthesis of bio-functionalized three-dimensional titania nanofibrous structures, using femtosecond laser ablation
}

\author{
Amirhossein Tavangar ${ }^{\mathrm{a}}$, Bo Tan ${ }^{\mathrm{b}}$, K. Venkatakrishnan ${ }^{\mathrm{a}, *}$ \\ ${ }^{a}$ Department of Mechanical and Industrial Engineering, Ryerson University, 350 Victoria Street, Toronto, ON M5B 2K3, Canada
}

${ }^{\mathrm{b}}$ Department of Aerospace Engineering, Ryerson University, 350 Victoria Street, Toronto, ON M5B 2K3, Canada

\section{A R T I C L E I N F O}

\section{Article history:}

Received 26 November 2010

Received in revised form 8 February 2011

Accepted 13 February 2011

Available online $\mathrm{xxxx}$

\section{Keywords:}

Osseointegration

Titanium oxide

Titania nanofibers

Laser ablation

Surface modification

Three-dimensional nanostructure

\begin{abstract}
A B S T R A C T
The primary objective of current tissue regeneration research is to synthesize nano-based platforms that can induce guided, controlled, and rapid healing. Titanium nanotubes have been extensively considered as a new biomaterial for biosensors, implants, cell growth, tissue engineering, and drug delivery systems. However, cell adhesion to nanotubes is poor due to their chemical inertness, as well as the one-dimensional structure, and surface modification is required to enhance nanotube-cell interaction. While there have been a considerable number of studies on growing titanium nanotubes, synthesizing a three-dimensional $\left(3-\mathrm{B}_{2}\right)$ nano-architecture which can act as a growth support platform for bone and stem cells has not been reported so far. Therefore, we present a novel technique to synthesize and grow $3-\mathrm{B}_{\mathrm{A}}$ titania interwoven nanofibrous structures on a titanium substrate using femtosecond laser irradiation under ambient conditions. This surface architecture incorporate the functions of $3-\mathrm{D}_{\mathbf{\Lambda}}$ nano-scaled topography and modified chemical properties to improve osseointegration while at the same time leaving space to deliver other functional agents. The results indicate that laser pulse repetition can control the density and pore size of engineered nanofibrous structures. In vitro experiments reveal that the titania nanofibrous architecture possesses excellent bioactivity and can induce rapid, uniform, and controllable bone-like apatite precipitation once immersed in simulated body fluid (SBF). This approach ing $3-\mathrm{D}_{\alpha}$ titania nanofibrous structures suggests considerable promise for the promotion of Ti interfacial properties to develop new functional biomaterials for various biomedical applications.
\end{abstract}

(c) 2011 Acta Materialia Inc. Published by Elsevier Ltd. All rights reserved.

\section{Introduction}

Nanofiber and nanotube architectures with high surface to volume ratios show functional and unique properties compared with those of their bulk counterparts. In particular, titania nanofiber and nanotube structures are of a great interest due to their proven biocompatibility, thermal stability, and corrosion resistance. They can be used for a number of applications, such as gas sensors, solar cells, implant surface modifications, tissue engineering, implantable drug delivery systems, and other medical devices [1-3]. Titania nanotube films have been widely recognized as growth support substrates for bone and stem cells, for the prevention of bacterial adhesion, and for enhancing blood clotting to control hemorrhaging. Recent in vivo and in vitro studies have demonstrated that surfaces comprised of nanotube platforms exhibit additional biological effects by integrating the oxide and apatite nanocrystals and also by improving cell-material interactions [1,4-6].

\footnotetext{
* Corresponding author. Tel.: +1 416979 5000/4984; fax: +1 4169795265.

E-mail address: venkat@ryerson.ca (K. Venkatakrishnan).
}

Titania nanotubes have been synthesized by several techniques, such as anodization [7], template-based synthesis [8], sol-gel transformation [9], and hydrothermal synthesis [10]. Among these, anodization continues to excite interest due to the simplicity of material preparation, as well as the greater control over the synthesis process in comparison with other methods. However, a multiple step process is needed and material preparation is comparatively complex owing to the long process time and high temperature [11]. Also, the as-anodized nanotubes are amorphous and a high temperature annealing step is required to form the crystalline phase [12]. Furthermore, previous research has clearly indicated that additional surface modification of titania nanotubes is required to further improve their biocompatibility [1]. With respect to tissue regeneration, three-dimensional $\left(3-\mathrm{D}_{1}\right)$ porous structures would be more promising for scaffold systems than onedimensional nanotubes, owing to their porous and interwoven structure. The merits of a surface comprised of interwoven ultrafine nanofibrous structures would be high porosity, a variable pore size distribution, a high surface to volume ratio and, most importantly, morphological similarity to natural extracellular matrix (ECM) [13]. 

was evaluated by soaking the samples in SBF with ionic concentrations nearly equal to human blood plasma (Table 1). A modified ber density on the surface could be controlled through adjustment of the laser parameters, such as laser pulse repetition and dwell time. The morphology, phase analyses, and interfacial properties of the synthesized nanofibrous structures have been characterized by scanning electron microscopy (SEM) followed by energy dispersive X-ray spectroscopy (EDS), transmission electron microscopy (TEM), X-ray diffraction (XRD) analysis, and contact angle measurement. The bone-like apatite-inducing ability of Ti surfaces with different morphology has been evaluated using simulated body fluid (SBF).

\section{Experimental section}

\subsection{Laser processing and generation of nanofibrous structures}

A titania nanofibrous layer has been formed on Ti samples using single point femtosecond laser irradiation under ambient conditions. Substrate samples $10 \times 10 \times 2 \mathrm{~mm}$ were cut from grade 2 (ASTM B265) pure Ti sheet using a diamond saw with oil lubrication. The samples were then ground progressively using 180 , $320,400,600$, and 1200 grit silicate-carbon papers to remove macro-level surface defects and contaminants. Once ground they were ultrasonically cleaned in distilled water and dried in a desiccator. Lastly, specimens were irradiated by laser beam at laser pulse repetitions of 4,8 , and $12 \mathrm{MHz}$ to generate nanofibrous structures of different densities and with different pore sizes. The laser pulse width, power and irradiation dwell time were $214 \mathrm{fs}$, $15 \mathrm{~W}$, and $5 \mathrm{~ms}$, respectively. The laser source used in this experiment was a $1040 \mathrm{~nm}$ wavelength direct diode pumped, Yb doped fiber amplified ultrafast system. Due to the solid-state operation and high spatial mode quality of fiber lasers our system produced low noise performance. In addition, the laser parameters, including laser repetition rate, pulse width, and beam power, are computer controlled, allowing accurate interaction in the performed experiments. Fig. 1 is the schematic diagram of the experimental setup and procedure.

Laser irradiation of a target creates a heated region, which causes vaporization, leading to formation of plasma plume. As the plume expands outwards its temperature and pressure decrease, resulting in condensation, which leads to nucleation. At laser pulse repetition rates higher than the nanoparticle formation threshold successive laser pulses irradiating the target surface maintain a continuous flow of the vapor plume, which consequently increases the nucleus density. The large number of nuclei leads to the growth of nanoparticles rather than micro-scale droplets, which will aggregate into interwoven nanofibrous structures after further collisions.

\subsection{Sample soaking in SBF for in vitro assessment}

simulated body fluid ( $\mathrm{m}-\mathrm{SBF}$ ) was prepared by dissolving the following reagents in sequence in distilled water: $\mathrm{NaCl}, \mathrm{NaHCO}_{3}$, $\mathrm{Na}_{2} \mathrm{CO}_{3}, \mathrm{KCl}, \mathrm{K}_{2} \mathrm{HPO}_{4} \cdot 3 \mathrm{H}_{2} \mathrm{O}, \mathrm{MgCl}_{2} \cdot 6 \mathrm{H}_{2} \mathrm{O}, \mathrm{CaCl}_{2}$, and $\mathrm{Na}_{2} \mathrm{SO}_{4}$. The solution was buffered to $\mathrm{pH} 7.40$ with HEPES and $1 \mathrm{M} \mathrm{NaOH}$ at $37^{\circ} \mathrm{C}[14]$. Each Ti sample was then placed in a sterilized polyethylene container with $30 \mathrm{ml} \mathrm{SBF}$ and kept in an incubator at $37^{\circ} \mathrm{C}$ for 1 or 3 days. After exposure the samples were removed and washed thoroughly with distilled water and dried in a desiccator for further characterization.

\subsection{Surface characterization}

The morphology of the nanofibrous structures before and after
SBF soaking was characterized using SEM followed by EDS analysis. Nanoparticle aggregation and the size of the nanofibers were analyzed by TEM. In order to separate the nanostructures from the substrate samples were immersed in isopropanol solution and ultrasound vibration was applied. Then a drop of the dispersed nanofiber solution was placed on a copper mesh and allowed to dry in a desiccator.

Phase analysis of the synthesized structures was performed using XRD. The X-ray source was a $\mathrm{Cu} K_{\alpha}$ rotating anode generator with a parallel focused beam and three-circle diffractometer with a two-dimensional detector. The average wavelength of the X-rays was $1.54184 \AA$. Phi scans with widths of $60^{\circ}$ were done with the detector at four different swing angles for each sample in order to obtain a profile with a $2 \theta$ range of $10.5-104^{\circ}$.

\subsection{Contact angle measurement}

The wetting properties of the nanofibrous layer were studied by dynamic contact angle measurements. Samples were fixed and a droplet of distilled water was applied to the surface. Images of each drop on the surfaces were recorded using a digital microscope. The contact angles were determined from the images using axisymetric drop shape analysis (ADSA-NA) methodology [15]. The mean value of the contact angles was calculated from five individual measurements taken at different locations on the substrates.

\section{Results and discussion}

\subsection{The structure of the nanofibrous layer}

The structure of the nanofibrous layer is influenced by various laser parameters, such as laser fluence, laser pulse repetition and laser pulse dwell time. In this study we have investigated the effect of laser pulse repetition on porosity and size of the synthesized nanofibers. Fig. 2 shows SEM images of the nanofibrous layer generated on the Ti4 surface at a pulse repetition rate of $4 \mathrm{MHz}$. A close-up view of the layer shows that it consisted of self-assembled closed rings and bridges in which nanoparticles are fused together. The pores are interconnected, with sizes of 900-1000 nm. Additional experiments have been performed with different laser repetition rates of 8 and $12 \mathrm{MHz}$ (Fig. 3). The pore sizes range from approximately 700 to $800 \mathrm{~nm}$ for the nanofibrous layers generated on Ti8, while they are about $650-750 \mathrm{~nm}$ for those synthesized on the surface of Ti12. In TEM images of a single nanofiber one can observe a high degree of nanoparticle aggregation (Fig. 4). The nanoparticles are aggregated together in a semi-solid state rather than loosely agglomerated. Therefore, the bonds between the particles themselves and with the Ti substrate are assumed to be strong. The diameter of the nanofibers is approximately $16-20 \mathrm{~nm}$ for Ti12 and increases as the repetition rate is reduced to $4 \mathrm{MHz}$. These results indicate that a reduction in laser pulse repetition rate leads to an increase in the density of the nanofibrous structures as well 


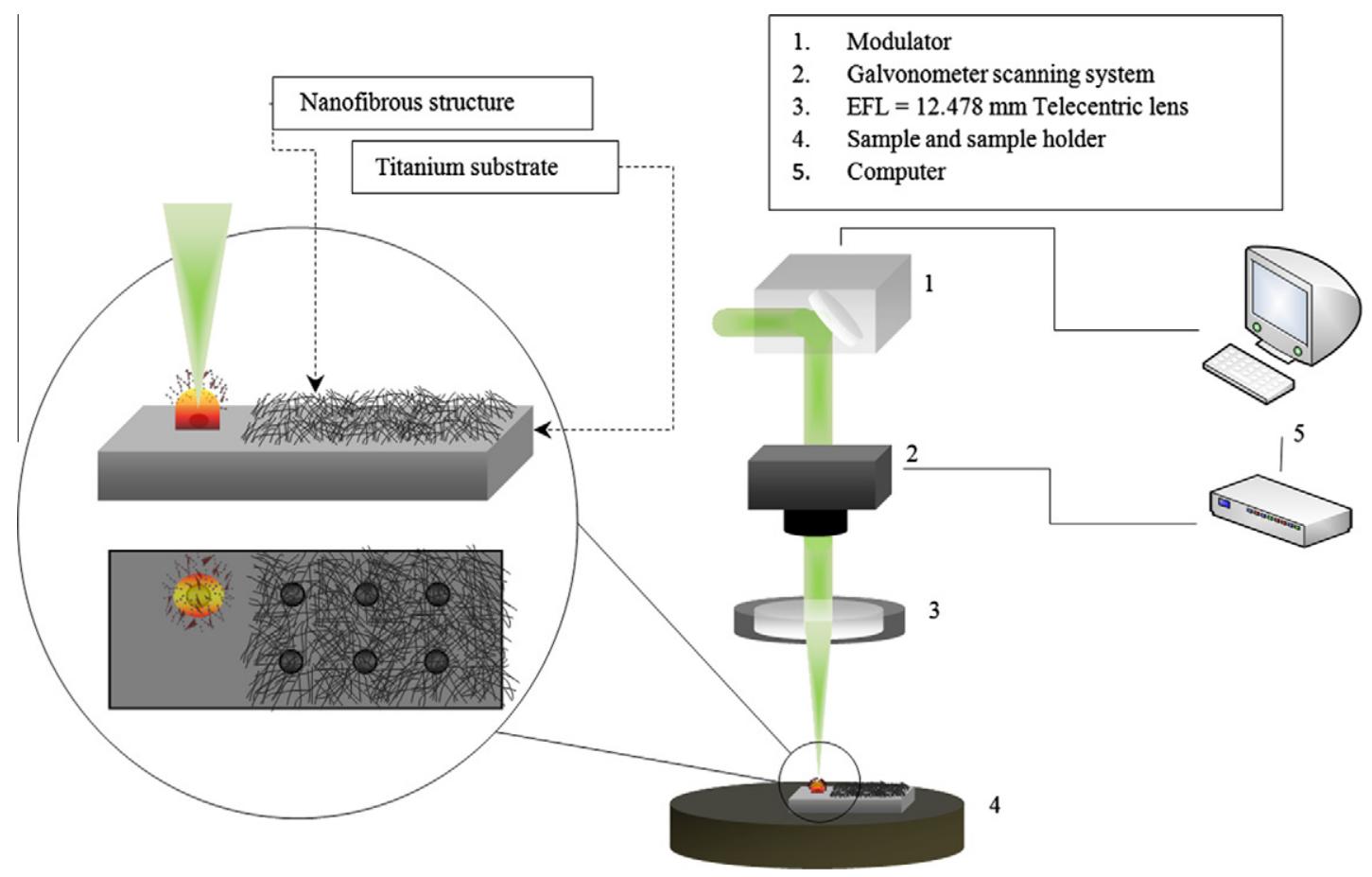

Fig. 1. Experimental set-up.

Table 1

Ion concentration of SBF in comparison with blood plasma.

\begin{tabular}{lcr}
\hline \multirow{2}{*}{ Ion } & Ion concentration $(\mathrm{mM})$ & \\
\cline { 2 - 3 } & Blood Plasma & $\mathrm{SBF}$ \\
\hline $\mathrm{Na}^{+}$ & 142.0 & 142.0 \\
$\mathrm{~K}^{+}$ & 5.0 & 5.0 \\
$\mathrm{Mg}^{2+}$ & 1.5 & 1.5 \\
$\mathrm{Ca}^{2+}$ & 2.5 & 2.5 \\
$\mathrm{Cl}^{-}$ & 103.0 & 103.0 \\
$\mathrm{HCO}_{3}{ }^{-}$ & 27.0 & 10.0 \\
$\mathrm{HPO}_{4}{ }^{2-}$ & 1.0 & 1.0 \\
$\mathrm{SO}_{4}{ }^{2-}$ & 0.5 & 0.5 \\
$\mathrm{pH}$ & $7.2-7.4$ & 7.4 \\
\hline
\end{tabular}
as in the size of nanoparticles. This is due to the fact that at constant laser power and laser spot size pulse energy drops off with an increase in pulse repetition rate, which results in a reduction in material ablation and nanoparticle size.

In order to evaluate the crystal structure of the nanofibrous layer XRD analysis was conducted. Fig. 5 compares the XRD patterns of an unprocessed Ti sample and the nanofibrous layer generated on the Ti4 surface. The unprocessed Ti sample is entirely composed of $\alpha$-phase titanium ( $\alpha$-Ti), while the nanofibrous structure pattern indicates that it consists of tetragonal $\mathrm{TiO}_{2}$ (rutile and anatase) and cubic TiO (hongquiite). The sharp peaks in the patterns can be associated with the high crystallinity of the oxide phases. Titania exists in two main crystallographic forms, anatase (A) and rutile (R) [16]. The XRD peaks at $2 \theta=25.28^{\circ}$ (A101) and $2 \theta=27.4^{\circ}$ (R110) are often interpreted as the characteristic peaks of the anatase and rutile crystal phases, respectively $[16,17]$. The peak at $2 \theta=43.37^{\circ}$ may be attributed to TiO. It has been reported that titanium oxide on the implant surface would greatly improve apatite precipitation [18].

\subsection{The apatite-inducing ability of different surface morphologies}

SEM micrographs of the apatite-inducing ability of different surfaces are shown in Figs. 6-8. The unprocessed Ti sample did not induce any apatite deposition after 3 days soaking in SBF, whereas Ti4, Ti8, and Ti12 showed high apatite-inducing ability, even after 1 day of immersion in SBF.

As illustrated in Fig. 7a for Ti12, although the apatite spheroids were too small to be detected, the whole nanofibrous surface was covered with apatite precipitation after 1 day of soaking. However,
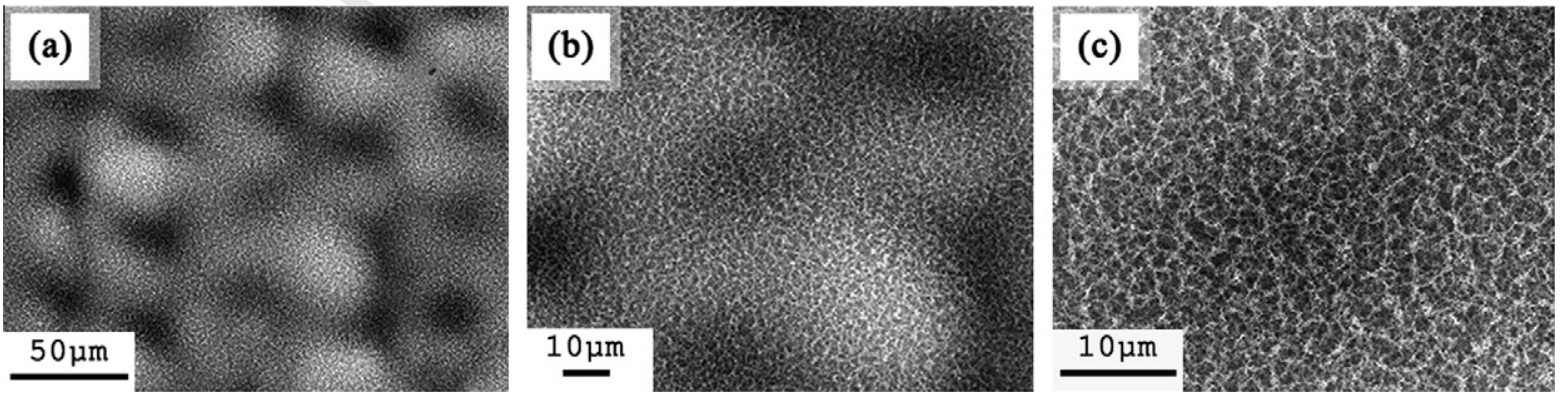

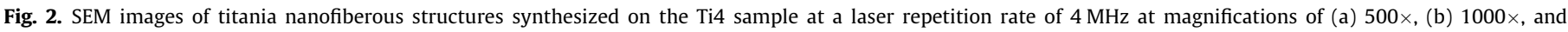
(c) $2500 \times$. 

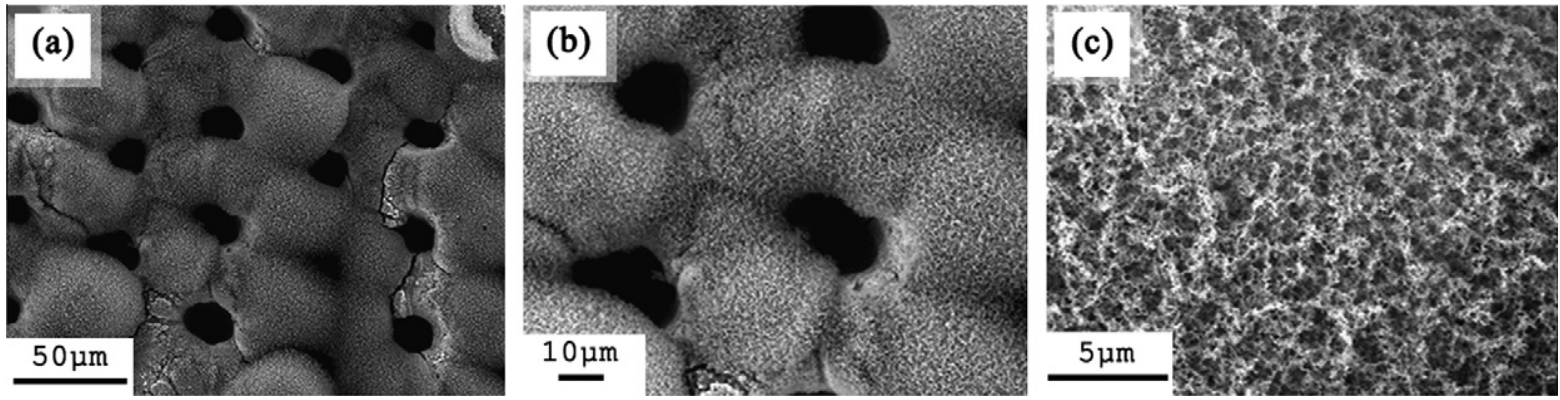

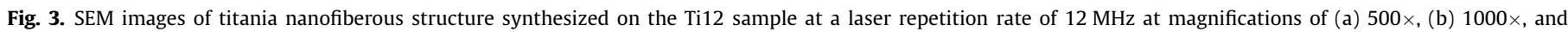
(c) $5000 \times$.
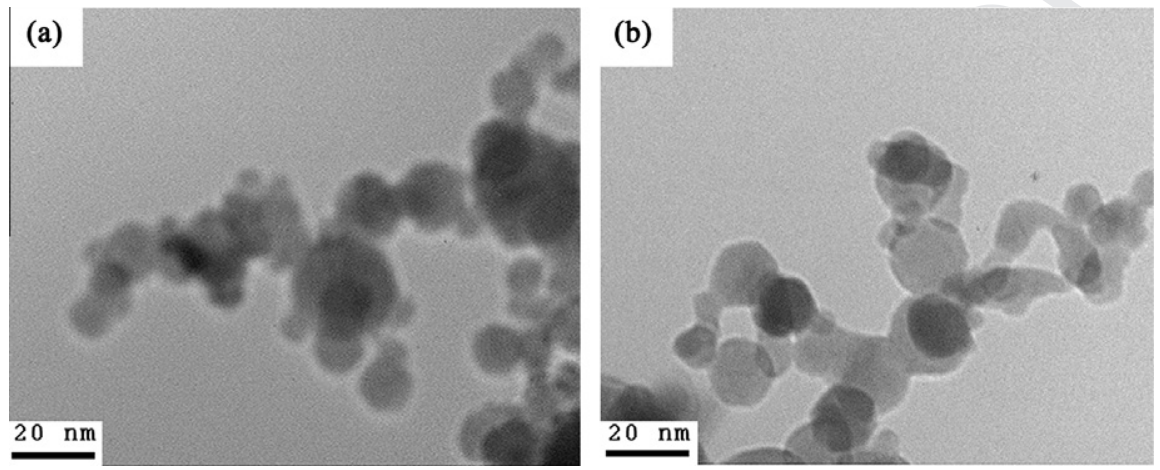

Fig. 4. TEM images of Ti nanofibers synthesized at repetition rates of (a) $12 \mathrm{MHz}$ and (b) $8 \mathrm{MHZ}$.
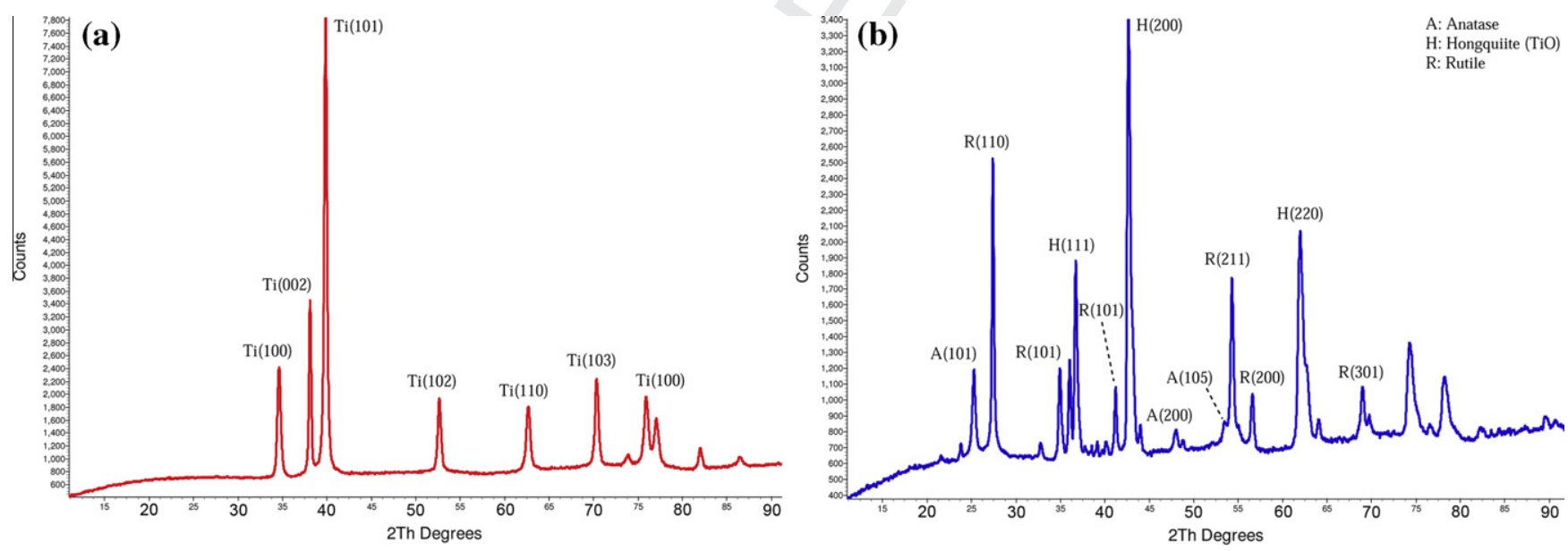

Fig. 5. X-ray diffraction patterns of (a) an unprocessed Ti sample and (b) the titania nanofibrous layer generated on the Ti4 sample after laser irradiation.

after 3 days immersion the precipitation layer became thick, and scattered apatite globules with a diameter of $22 \mu \mathrm{m}$ were observed on the Ti12 surface. On the other hand, a thick precipitation layer made of apatite spheroids with a diameter of $2 \mu \mathrm{m}$ deposited on the surfaces of the Ti4 and Ti8 samples even after 1 day of immersion in SBF (Fig. 8a). It can be observed that all the pores have been filled by apatite precipitation. However, the precipitation layer is not uniform for Ti8 in comparison with Ti4. After soaking for 3 days all surfaces were covered by dense homogeneous apatite layers composed of numerous apatite spheroids with a diameter of $5 \mu \mathrm{m}$ (Figs. 7 and 8b). Several apatite spheroids as large as $25 \mu \mathrm{m}$ in diameter can be observed on both the Ti4 and the Ti8 surfaces after 3 days. The uniform apatite precipitation on the nanofibrous structure indicates that the reproducibility of apatite crystallization on the nanofibers is very high.

EDX analysis of the composition of the apatite layer deposited after 1 day of immersion in SBF for Ti4 indicates the presence of titanium, calcium, phosphorous, and oxygen, as shown in Fig. 9a. The molar $\mathrm{Ca} / \mathrm{P}$ ratio was 1.31 , which is attributed to octacalcium phosphate (OCP) $\left(\mathrm{Ca}_{8} \mathrm{H}_{2}\left(\mathrm{PO}_{4}\right)_{6} \cdot 5 \mathrm{H}_{2} \mathrm{O}\right)$. OCP is considered to be a necessary precursor in the crystallization of bone-like apatite $[19,20]$. As depicted in Fig. 9b, EDX analysis of the Ti4 sample after immersion in SBF for 3 days shows rich phases of calcium and phosphorous with traces of magnesium. It is interesting that the titanium phase is barely detectable by EDX due to the fact that the deposited apatite layer is thick and compact. The molar $\mathrm{Ca} / \mathrm{P}$

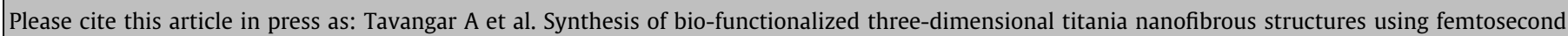
laser ablation. Acta Biomater (2011), doi:10.1016/j.actbio.2011.02.020 

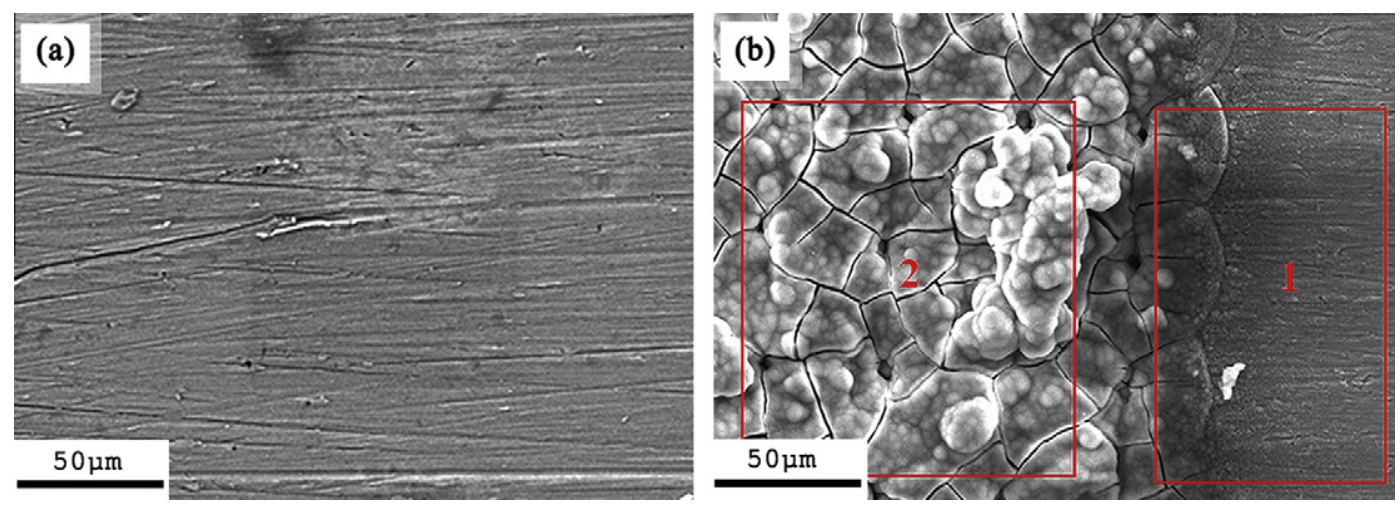

Fig. 6. (a) SEM image of surface morphology of an unprocessed Ti sample after 1 day soaking in SBF and (b) SEM image of the Ti4 morphology comparing the different apatiteinducing abilities of (1) the unprocessed area and (2) the nanofibrous layer after soaking for 3 days.
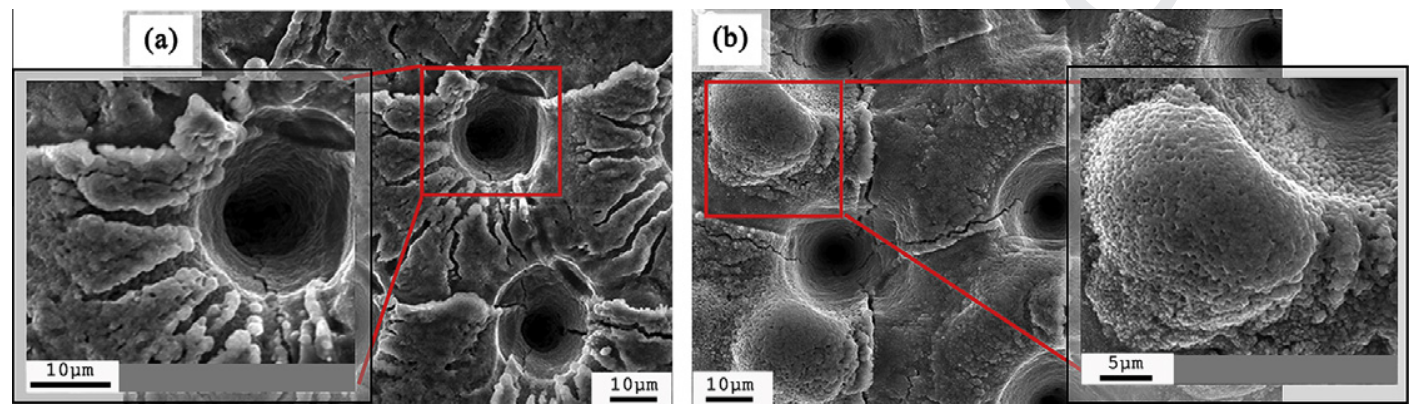

Fig. 7. SEM image of the Ti12 surface morphology after soaking in SBF for (a) 1 day and (b) 3 days.
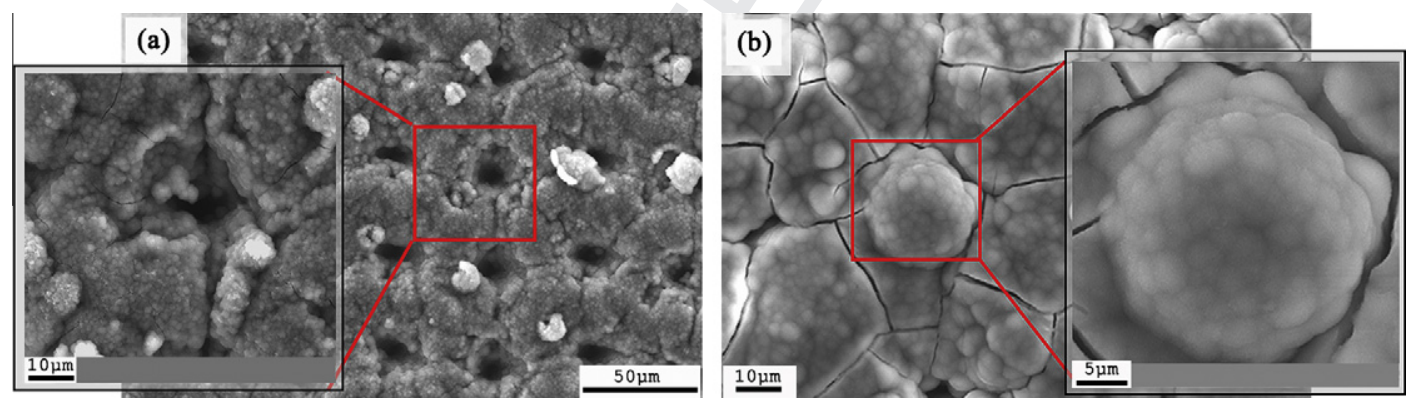

Fig. 8. SEM images of the Ti4 surface morphology after soaking in SBF for (a) 1 day and (b) 3 days.

(a)

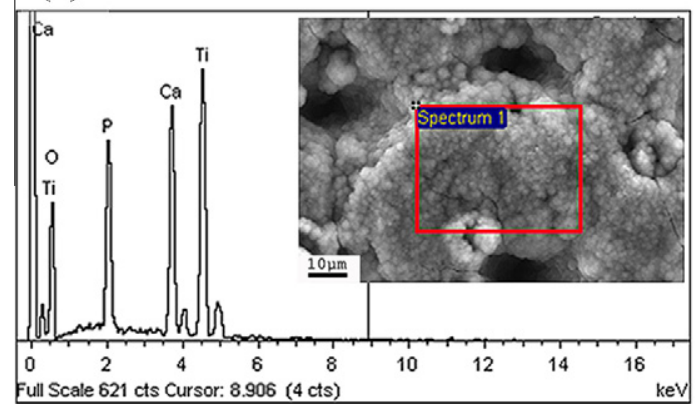

(b)

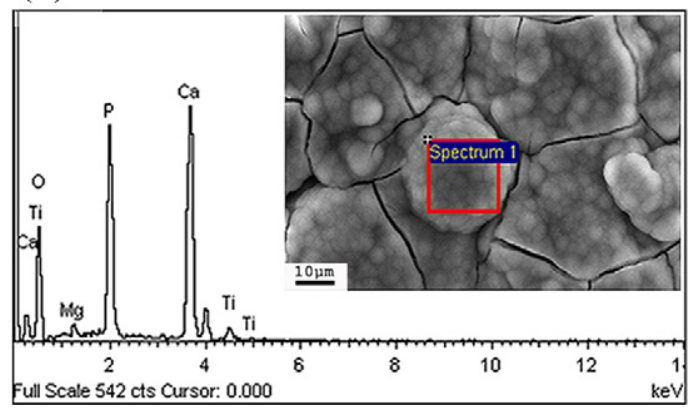

Fig. 9. EDS analysis of Ti4 after soaking in SBF for (a) 1 day and (b) 3 days.

ratio for the precipitated apatite layer after 3 days immersion in SBF was approximately 1.63 , which corresponds to hydroxyapatite (HA) $\left(\mathrm{Ca}_{5} \mathrm{H}_{2}\left(\mathrm{PO}_{4}\right)_{3} \cdot \mathrm{OH}\right)$. HA, which has a composition similar to the mineral phase of bone, is by far the most abundant inorganic phase in the human body [21]. It has been demonstrated that bone-like HA possesses good osteoconductivity and has a high affinity for living bone cells $[20,22]$.

Please cite this article in press as: Tavangar A et al. Synthesis of bio-functionalized three-dimensional titania nanofibrous structures using femtosecond laser ablation. Acta Biomater (2011), doi:10.1016/j.actbio.2011.02.020 
Fig. 10 contrasts the XRD patterns of Ti4 after soaking in SBF for 1 and 3 days. The broad peak at $2 \theta=32.6^{\circ}$ is attributed to overlap of the (2 11 ), ( 1112$),\left(\begin{array}{lll}3 & 0 & 0\end{array}\right)$, and (2 02 ) crystal planes, and the peak at $2 \theta=25.9^{\circ}$ is assigned to the $\left(\begin{array}{lll}0 & 02\end{array}\right)$ diffraction peak of HA. As seen in Fig. 10a, the apatite layer was thick enough to be detected even after 1 day of immersion in SBF. However, the peak at $2 \theta=25.9^{\circ}$ was been detected for the deposited layer after 1 day of soaking. The intensity of the peaks increased for the apatite layer precipitated after 3 days, as shown in Fig. 10b. It can be observed that the intensity of the peak attributed to the HA diffraction plane at $2 \theta=32.6^{\circ}$ for the sample soaked for 3 days is dramatically increased and became sharper, indicating a larger crystal size.

In biological environments the energy of surfaces plays a crucial role in the mediation of solute adsorption and cell adhesion. Biological interactions between the biomaterial surface and a biological medium are closely associated with wettability [1,23]. The wettability of unprocessed Ti substrates, Ti4, Ti8, and Ti12, has been studied by sessile drop contact angle measurement of a distilled water droplet. CA measurements of an unprocessed Ti sample as well as the Ti4, Ti8, and Ti12 are depicted in Fig. 11. Contact angles $<4^{\circ}$ on the titania nanofibrous layer on Ti4 indicates superhydrophilic properties, in contrast to those of the unprocessed Ti surface $(66.7 \pm 1)$. The almost complete spreading of water droplets on the surface covered with the nanofibrous layer is observed during the contact angle measurements for all samples.

The above mentioned results of this study show that titania nanofibrous layers generated on a Ti surface using laser irradiation greatly enhance the wettability of the surface, which consequently increases the apatite-inducing ability. Furthermore, the results indicate that the density and porosity of the nanofibrous layer affect the apatite-inducing ability of the surface. Due to the high temperatures used and the presence of atmospheric oxygen, nanofibers become oxidized and covered by a titanium oxide layer a few nanometers thick. XRD has shown that the oxide layer consisted of $\mathrm{TiO}_{2}$ (rutile and anatase) and cubic TiO (hongquiite). Several studies have demonstrated that both rutile and anatase enhance apatite-inducing ability, which consequently improves bioactivity and osteointegeration of Ti surfaces [24-26].

The results of this study have shown that apatite nucleation and deposition happened even after 1 day. They have also demonstrated that a surface with a higher amount of nanofibrous structure results in more apatite deposition. The mechanism for rapid apatite deposition on a nanofibrous layer can be attributed to the $3 \mathrm{~B}_{\alpha}$ structure of the layer as well as the surface chemistry. Nanofibrous structures with high specific surface areas enhance

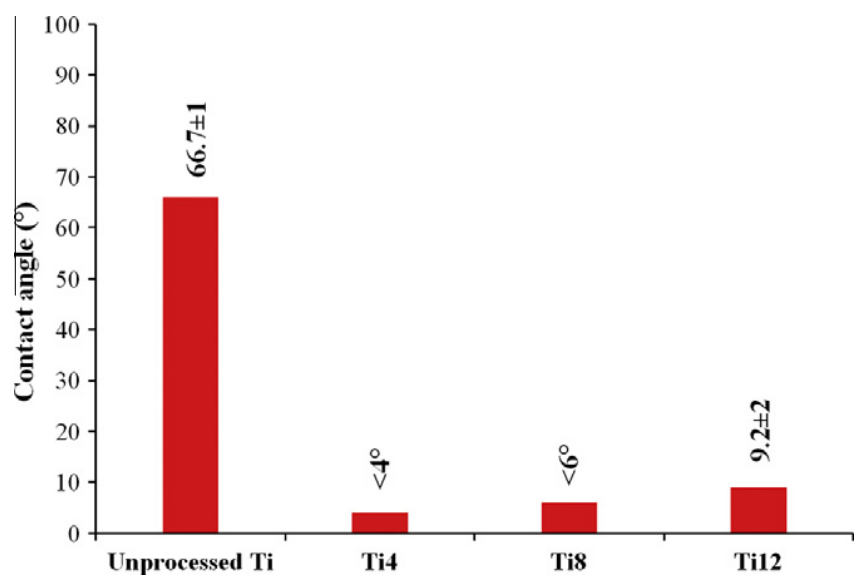

Fig. 11. Sessile drop water contact angle measurement for an unprocessed $\mathrm{Ti}$ substrate and the titania nanofibrous layer on the Ti4, Ti8, and Ti12 samples.

the wettability of the surface when soaked in SBF. Wettability improves the reaction of water molecules present in the SBF with titanium oxides on the nanofiber surface, leading to surface hydroxylation. Hydroxylated titanium oxides are insoluble and result in the formation of $\mathrm{Ti}-\mathrm{OH}$ groups on the surface, which is believed to promote apatite nucleation [27-29]. Reaction of the $\mathrm{Ti}-\mathrm{OH}$ layer with aqueous solution changes the surface charge. At low $\mathrm{pH}(<4)$ the formation of $[\mathrm{Ti}-\mathrm{OH}]^{+}$from basic $\mathrm{Ti}-\mathrm{OH}$ results in a positive surface charge, while at high $\mathrm{pH}(>9)$ acidic $\mathrm{Ti}-\mathrm{OH}$ gives off a proton and yields $[\mathrm{Ti}-\mathrm{OH}]^{-}$, leading to a negative surface charge. At pH levels between 4 and 9 both basic and acidic hydroxides coexist on the surface [30]. Since the isoelectric point (IEP) of titanium oxide is 5-6 at neutral $\mathrm{pH}$, in our case SBF (7.4), the surface is slightly negative due to deporotonation of acidic hydroxides. A negatively charged surface attracts $\mathrm{Ca}^{2+}$ cations with the formation of calcium hydroxide. Subsequently phosphate ions $\left(\mathrm{PO}_{4}{ }^{3-}\right)$ present in the SBF react with the calcium hydroxide layer, resulting in apatite nuclei formation [31]. Since SBF is a supersaturated solution of $\mathrm{Ca}$ and $\mathrm{P}$ ions, bone-like apatite spheroids grow spontaneously on apatite nuclei. The bone-like apatite layer acts as a template for cell migration, integration, and differentiation at the biomaterial-tissue interface, which in turn improves bioactivity and osseointegration of $\mathrm{Ti}$ surfaces. In the current work nanofibrous structures, owing to their high surface area, promoted numerous sites of apatite nucleation, which led to a decrease in the deposition time as well as an increase in the amount of apatite
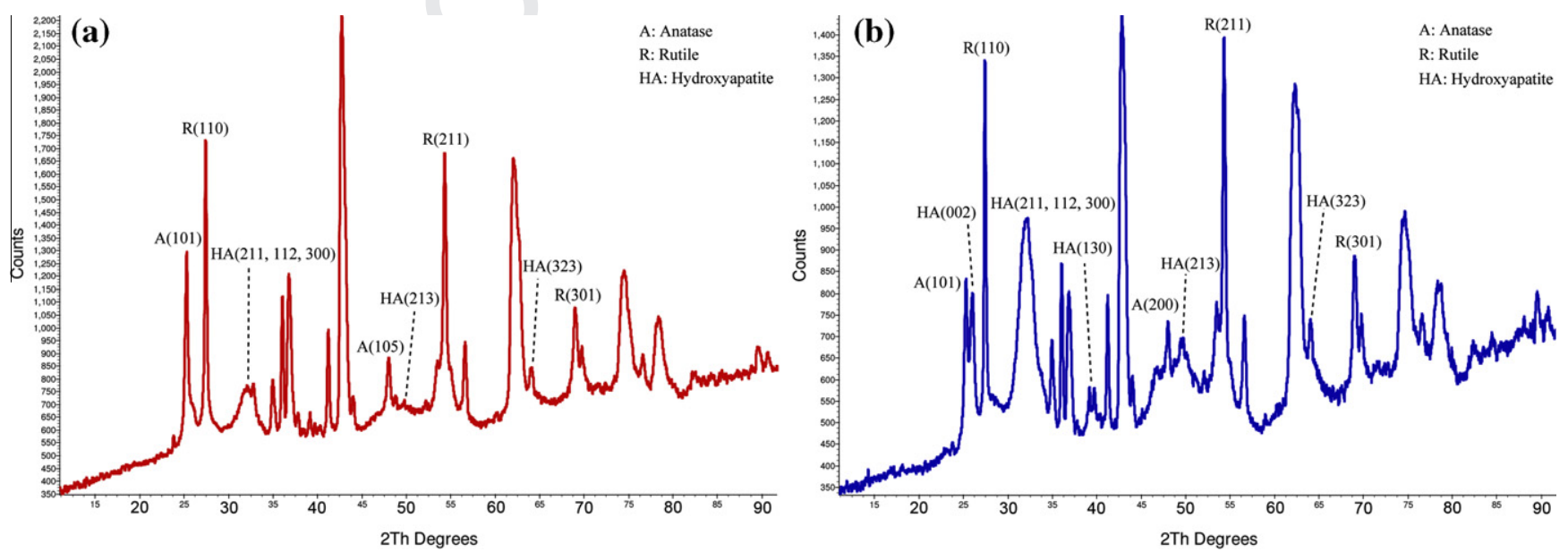

Fig. 10. XRD analysis of Ti4 after soaking in SBF for (a) 1 day and (b) 3 days. 
deposited. Conversely, the low surface energy and relative rarity of hydroxides on the surface of the unprocessed Ti substrate resulting in areduced apatite-inducing ability. Hence, no apatite deposition was observed on the unprocessed Ti, even after 3 days. A nanofibrous layer with a rapid apatite-inducing capability is expected to advance bone formation when implanted in a living body.

\section{Conclusion}

In this study a single method of synthesizing titania nanofibrous structures on Ti substrates using a high repetition femtosecond laser was introduced. It was shown that a thick, homogeneous HA layer was deposited on a Ti surface with a titania nanofibrous layer after 3 days immersion in SBF. The results indicated that the surface morphology as well as the surface physico-chemical properties (surface reactivity and wettability) of the nanofibrous layer significantly influences the apatite-inducing capability. It as, demonstrated that laser ablation of the Ti surface resulted in the formation of rutile and anatase phases that enatite deposition and cell adhesion on the Ti substrate. It was shown that the density and porosity of the nanofibrous layer could be controlled by varying the laser pulse repetition rate. A surface with a denser nanofiber layer showed greater apatite-inducing ability. It is expected that the $3-\mathrm{D}_{\curlywedge}$ titania nanofibrous layer will improve the properties of titanium and advance the development of new biomedical devices for diverse biomedical applications, such as tissue scaffolds, orthopedic and dental implants, to control clotting, and to provide a platform to prevent bacterial adhesion.

\section{Acknowledgement}

This research was funded by Natural Science and Engineering Research Council of Canada.

\section{Appendix A. Figures with essential colour discrimination}

Certain figures in this article, particularly Figures 1, 5, 6, 7, 8, 9, 10 and 11 , are difficult to interpret in black and white. The full colour images can be found in the on-line version, at doi:10.1016/ j.actbio.2011.02.020.

\section{Appendix B. Supplementary data}

Supplementary data associated with this article can be found, in the online version, at doi:10.1016/j.actbio.2011.02.020.

\section{References}

[1] Vasilev K, Poh Z, Kant K, Chan J, Michelmore A, Losic D. Tailoring the surface functionalities of titania nanotube arrays. Biomaterials 2010;31(3):532-40.

[2] Yoriya S, Mor GK, Sharma S, Grimes CA. Synthesis of ordered arrays of discrete, partially crystalline titania nanotubes by $\mathrm{Ti}$ anodization using diethylene glycol electrolytes. J Mater Chem 2008;18(28):3332-6.

[3] Wang CC, Yu CY, Kei CC, Lee CT, Perng TP. The formation of $\mathrm{TiO}_{2}$ nanowires directly from nanoparticles. Nanotechnology 2009;20 (28),

[4] Palmquist A, Omar OM, Esposito M, Lausmaa J, Thomsen P. Titanium oral implants: surface characteristics, interface biology and clinical outcome. J R Soc Interface 2010;7:S515-27.

[5] Dalby MJ, McCloy D, Robertson M, Wilkinson CDW, Oreffo ROC Osteoprogenitor response to defined topographies with nanoscale depths. Biomaterials 2006;27(8):1306-15.
[6] Variola F, Yi JH, Richert L, Wuest JD, Rosei F, Nanci A. Tailoring the surface properties of Ti6Al4V by controlled chemical oxidation. Biomaterials 2008;29(10):1285-98.

[7] Mor GK, Varghese OK, Paulose M, Grimes CA. Transparent highly ordered $\mathrm{TiO}_{2}$ nanotube arrays via anodization of titanium thin films. Adv Funct Mater 2005;15(8):1291-6.

[8] Liu SM, Gan LM, Liu LH, Zhang WD, Zeng HC. Synthesis of single-crystalline $\mathrm{TiO}_{2}$ nanotubes. Chem Mater 2002;14(3):1391-7.

[9] Lei Y, Zhang LD, Meng GW, Li GH, Zhang XY, Liang CH, et al. Preparation and photoluminescence of highly ordered $\mathrm{TiO}_{2}$ nanowire arrays. Appl Phys Lett 2001;78(8):1125-7.

[10] Yao BD, Chan YF, Zhang XY, Zhang WF, Yang ZY, Wang N. Formation mechanism of $\mathrm{TiO}_{2}$ nanotubes. Appl Phys Lett 2003;82(2):281-3.

[11] Fahim NF, Sekino T. A novel method for synthesis of titania nanotube powders using rapid breakdown anodization. Chem Mat 2009;21(9):1967-79.

[12] Rani S, Roy SC, Paulose M, Varghese OK, Mor GK, Kim S, et al. Synthesis and applications of electrochemically self-assembled titania nanotube arrays. Phys Chem Chem Phys 2010;12(12):800-2800.

[13] Christenson EM, Anseth KS, van den Beucken LJJP, Chan CK, Ercan B, Jansen JA et al. Nanobiomaterial applications in orthopedics. J Orthop Res 2007;25(1): $11-22$.

[14] Oyane A, Onuma K, Ito A, Kim HM, Kokubo T, Nakamura T. Formation and growth of clusters in conventional and new kinds of simulated body fluids. J Biomed Mat Res A 2003;64A(2):339-48.

[15] Kalantarian A, David R, Neumann AW. Methodology for high accuracy contact angle measurement. Langmuir 2009;25(24):14146-54.

[16] Jing LQ, Xin BF, Yuan FL, Xue LP, Wang BQ, Fu HG. Effects of surface oxygen vacancies on photophysical and photochemical processes of $\mathrm{Zn}$-doped $\mathrm{TiO}_{2}$ nanoparticles and their relationships. J Phys Chem B 2006;110(36):17860-5.

[17] Zhang QH, Gao L, Guo JK. Effects of calcination on the photocatalytic properties of nanosized $\mathrm{TiO}_{2}$ powders prepared by $\mathrm{TiCl}_{4}$ hydrolysis. Appl Catal B 2000;26(3):207-15.

[18] Das K, Balla VK, Bandyopadhyay A, Bose S. Surface modification of laserprocessed porous titanium for load-bearing implants. Scr Mater 2008;59(8):822-5.

[19] Jonasova L, Muller FA, Helebrant A, Strnad J, Greil P. Biomimetic apatite formation on chemically treated titanium. Biomaterials 2004;25(7/8): 1187-94.

[20] Choi SW, Zhang Y, Thomopoulos S, Xia YN. In vitro mineralization by preosteoblasts in poly(DL-lactide-co-glycolide) inverse opal scaffolds reinforced with hydroxyapatite nanoparticles. Langmuir 2010;26(14): $12126-31$.

[21] de Jonge LT, Leeuwenburgh SCG, Wolke JGC, Jansen JA. Organic-inorganic surface modifications for titanium implant surfaces. Pharm Res 2008;25(10): 2357-69.

[22] Rizzi SC, Heath DT, Coombes AGA, Bock N, Textor M, Downes S. Biodegradable polymer/hydroxyapatite composites: surface analysis and initial attachment of human osteoblasts. J Biomed Mater Res 2001;55(4):475-86.

[23] Chen XB, Li YC, Hodgson PD, Wen C. The importance of particle size in porous titanium and nonporous counterparts for surface energy and its impact on apatite formation. Acta Biomater 2009;5(6):2290-302.

[24] Yang BC, Uchida M, Kim HM, Zhang XD, Kokubo T. Preparation of bioactive titanium metal via anodic oxidation treatment. Biomaterials 2004;25(6): $1003-10$

[25] Wang XX, Hayakawa S, Tsuru K, Osaka A. Bioactive titania gel layers formed by chemical treatment of $\mathrm{Ti}$ substrate with $\mathrm{a}_{2} \mathrm{O}_{2} / \mathrm{HCl}$ solution. Biomaterials 2002;23(5):1353-7.

[26] Uchida M, Kim HM, Kokubo T, Fujibayashi S, Nakamura T. Structural dependence of apatite formation on titania gels in a simulated body fluid. Journal of Biomedical Materials Research A 2003;64A(1):164-70.

[27] Li PJ, Ohtsuki C, Kokubo T, Nakanishi K, Soga N, Degroot K. The role of hydrated silica, titania, and alumina in inducing apatite on implants. J Biomed Mater Res 1994;28(1):7-15.

[28] Kim HM, Miyaji F, Kokubo T, Nakamura T. Preparation of bioactive Ti and its alloys via simple chemical surface treatment. J Biomed Mater Res 1996;32(3):409-17.

[29] Song WH, Jun YK, Han Y, Hong SH. Biomimetic apatite coatings on micro-arc oxidized titania. Biomaterials 2004;25(17):3341-9.

[30] Rohanizadeh R, Al-Sadeq M, LeGeros RZ. Preparation of different forms of titanium oxide on titanium surface. effects on apatite deposition. J Biomed Mat Res A 2004;71A(2):343-52.

[31] Paital SR, Dahotre NB. Wettability and kinetics of hydroxyapatite precipitation on a laser-textured Ca-P bioceramic coating. Acta Biomater 2009;5(7): 2763-72. 